\title{
Breast cancer diagnosed before the 40 years: imaging findings and correlation with histology and molecular subtype
}

\author{
Deise Santiago Girão Eugênio, Juliana Alves Souza, Rubens Chojniak, Almir Galvão Vieira Bitencourt*, \\ Luciana Graziano and Elvira Ferreira Marques
}

\begin{abstract}
Background: To evaluate the imaging findings in patients with breast cancer diagnosed before age 40 and their correlation with histological type and molecular subtype.

Methods: A descriptive, retrospective, single-center study was conducted by reviewing imaging exams and medical records, after approval of the institution's Ethics Review Board. Among the 120 patients studied, 112 (93.3\%) had mammography, 113 (94.2\%) underwent ultrasonography and 105 (87.5\%) underwent breast magnetic resonance imaging (MRI). Histopathology data was performed in most cases after surgical resection, which was available for 113 patients (94.2\%).

Results: The mean age at diagnosis of primary breast cancer was 34 years. Most patients had no family history of breast cancer or ovarian cancer (60.7\%), and were symptomatic at diagnosis (75.6\%). The most common histological type was no-special type (NST) invasive carcinoma (73.8\%). Regarding the molecular subtype, luminal B was the most common (42.6\%), followed by triple negative (20.2\%). The malignant tumor was identified in $92.9 \%$ of patients who underwent mammography, $96.5 \%$ of patients submitted to ultrasound and $98 \%$ of those who performed MRI. MRI was superior to other methods in the evaluation of multifocal and multicentric lesions. There was no statistically significant association between imaging findings and molecular subtypes in the present study.

Conclusions: This study demonstrated that imaging methods play a fundamental role in the characterization of cases of breast cancer diagnosed in patients younger than 40 years. Despite the ultrasound has been the most widely used method, we found improved characterization of breast lesions when also used mammography and MRI.
\end{abstract}

Keywords: Breast neoplasms, Mammography, Mammary ultrasonography, Magnetic resonance imaging

\section{Background}

Breast cancer is the second most common cancer worldwide and the most common among women. The disease is mostly found in women after menopause, because about $75 \%$ of cases are diagnosed in women over the age of 50 . Despite being a relatively uncommon condition, current statistics point to the increased incidence of these tumors in young women $[1,2]$.

In women under 40 , the breast cancer may exhibit more aggressive behavior and poor prognosis $[3,4]$. In this group, the delay in the diagnosis of breast cancer is a

* Correspondence: almirgvb@yahoo.com.br

AC Camargo Cancer Center, Department of Imaging, R. Prof. Antonio Prudente, 211, São Paulo, SP 09015-010, Brazil common problem by many factors such as lack of awareness about the disease and consequent delay in health care demand, lack of screening programs in this age group, rapid tumor growth and dense breast parenchyma, which can hinder the identification of lesions in clinical examination $[5,6]$. Thus, imaging methods are essential in the diagnosis and monitoring of breast lesions, being ultrasound, mammography and magnetic resonance imaging (MRI) are the most used methods.

Knowledge of the clinical and imaging presentation of breast cancer in young women, in association with pathological aspects of these tumors, is important to improve the detection of breast lesions in this group. The objective of this study was to evaluate the imaging 
findings in patients with breast cancer diagnosed before age 40 and their correlation with histological type and molecular subtype.

\section{Methods}

A descriptive, retrospective, single-center study was conducted by reviewing imaging exams and medical records, after approval of the institution's Ethics Review Board. We included patients who was diagnosed with breast cancer and the age of 40 years, from November 2008 to August 2012. Among the 120 patients studied, 112 (93.3\%) had mammography, 113 (94.2\%) underwent ultrasonography and 105 (87.5\%) underwent breast MRI (92 performed mammography, ultrasonography and MRI; 14 performed mammography and ultrasonography; 6 performed mamography and MRI; 6 performed ultrasonography and MRI; 1 performed only ultrasonography and 1 performed only MRI). All patients that underwent mammography had standard views (cranial-caudal and medial-lateral oblique) and additional images when necessary. All sonographic examinations were performed with linear frequency probes between 7.5 and $12 \mathrm{MHz}$. MRI studies included were conducted in high-field systems (1.5 Tesla) with dedicated breast coil and use of intravenous paramagnetic contrast. The 5th edition of the American College of Radiology - Breast Imaging Report and Data System (ACRBIRADS) lexicon was used for radiological descriptors [7].

Histopathology data was performed in most cases after surgical resection, which was available for 113 patients (94.2\%). In the other cases $(n=7 ; 5.8 \%)$, data obtained through ultrasound-guided percutaneous core needle biopsy were used. The histological types were reported according to the World Health Organization (WHO) classification of tumors [8]. Multifocality was defined by the presence of additional malignant lesions in the same quadrant of the primary tumor. Multicentricity was defined as the presence of additional malignant lesions in the same breast in different quadrants of the primary tumor. According to the immunohistochemical profile, breast carcinomas were classified into four molecular subtypes: Luminal A (expression of estrogen / progesterone receptors and low proliferation index); Luminal B (positive receptor for estrogen and/or progestin with Her- 2 overexpression or high proliferation index); Her2 (negative hormone receptors and HER -2 overexpression) and; triple-negative (hormone receptor and Her- 2 negative). Pathologic diagnoses, including immunophenotype, were obtained from medical reports of patients. In the period of the study, the cut-off of $15 \%$ for Ki- 67 expression was routinely used to differentiate low and high proliferation index.

Statistical analyses were performed using SPSS for Windows, version 20.0 (SPSS Inc. Chicago, Illinois). Frequency analysis was performed to characterize the sample. The following tests were used to compare variables: chi-square test when both variables were categorical, and Student's $t$-test and Mann-Whitney test when one of the variables was continuous with and without normal distribution, respectively. $P$ value was considered statistically significant when equal to or less than 0.05 .

\section{Results \\ Sample description}

The age at diagnosis of breast cancer ranged from 24 to 39 years, with a mean of 34 years. Most patients $(n=73$; $60.7 \%$ ) had no family history of breast cancer or ovarian cancer, $11(9.0 \%)$ had a positive family history in first degree relatives and 35 patients (29.5\%) reported positive family history in second or third-degree relatives. Most patients $(n=92 ; 75.6 \%)$ were symptomatic at diagnosis and the presence of a palpable masse was the main complaint, reported by 78 patients (64\%).

Two patients had bilateral tumors, so 122 breast malignancies were diagnosed in the 120 included patients. Of these, 112 (9\%) were invasive tumor, 5 pure ductal carcinoma in situ (DCIS), 4 DCIS with microinvasion, and 1 Paget's disease. Histological type found in invasive tumors was no special type (NST) invasive carcinoma ( $n=90 ; 73.8 \%)$, followed by invasive lobular carcinoma ( $n=7 ; 5.7 \%)$, medullary carcinoma $(n=3 ; 2.5 \%)$, mucinous carcinoma $(n=3 ; 2.5 \%)$, invasive micropapillary carcinoma $(n=2 ; 1.6 \%)$, carcinoma with apocrine differentiation $(n=$ 2 ; $1.6 \%)$, metaplastic carcinoma $(n=1 ; 0.8 \%)$, tubular carcinoma $(n=1 ; 0.8 \%)$, tubulolobular carcinoma $(n=1$; $0.8 \%)$ and adenoid cystic carcinoma $(n=1 ; 0.8 \%)$. and other special types of invasive tumors (16.4\%). Multifocality and multicentric were observed in 18 cases (15\%) and 16 cases (13\%), respectively. The presence of in situ component was associated with invasive lesions in 78 cases (64\%), most with nuclear grade $3(71.8 \%)$ and associated with comedonecrosis (59\%). Regarding the molecular subtype, which was evaluated in 105 tumors, luminal B was the most common $(n=52 ; 42.6 \%)$, followed by triple negative in 25 cases (20.2\%), luminal A in 17 (13.9\%) and Her2 in $11(9.0 \%)$.

\section{Imaging findings}

The malignant tumor was identified in 104 among the 112 patients $(92.9 \%)$ who underwent mammography, including the two patients with bilateral tumor. Mammography identified bilateral tumors in one of these patients and only one lesion in the other. Thus, 9 malignant lesions $(7.9 \%)$ were not characterized at mammographic images. Regarding the density of breast parenchyma, 73 patients (65.2\%) showed heterogeneous or extremely dense breasts. The findings at mammography are described in Table 1. The presence of suspicious calcifications (isolated or associated with other findings) was 
Table 1 Description of mammographic findings

\begin{tabular}{|c|c|c|}
\hline Mammographic findings $(n=114)$ & $n$ & $\%$ \\
\hline Mass & 27 & 23,7 \\
\hline Mass with calcifications & 21 & 18,4 \\
\hline Suspicious calcifications & 18 & 15,8 \\
\hline Focal asymmetry & 17 & 14,9 \\
\hline Focal asymmetry with calcifications & 8 & 7,0 \\
\hline Architectural distortion with calcifications & 5 & 4,4 \\
\hline Architectural distortion & 3 & 2,6 \\
\hline Mass with architectural distortion & 3 & 2,1 \\
\hline Global asymmetry & 1 & 0,9 \\
\hline Negative findings & 9 & 7,9 \\
\hline Unknown & 2 & 1,7 \\
\hline Calcifications ( $n=52)$ & $n$ & $\%$ \\
\hline \multicolumn{3}{|l|}{ Morphology } \\
\hline Fine Pleomorphic & 21 & 40,4 \\
\hline Coarse heterogenous & 10 & 19,2 \\
\hline Amorphous & 7 & 13,5 \\
\hline Fine Linear & 3 & 5,8 \\
\hline \multicolumn{3}{|l|}{ Distribution } \\
\hline Grouped & 25 & 48,1 \\
\hline Segmental & 14 & 26,9 \\
\hline Regional & 3 & 5,8 \\
\hline Masses $(n=51)$ & $n$ & $\%$ \\
\hline \multicolumn{3}{|l|}{ Shape } \\
\hline Irregular & 23 & 45,1 \\
\hline Oval & 12 & 23,5 \\
\hline Round & 1 & 2,0 \\
\hline \multicolumn{3}{|l|}{ Margin } \\
\hline Circumscribed & 4 & 7,8 \\
\hline Obscured & 14 & 27,5 \\
\hline Microlobulated & 4 & 7,8 \\
\hline Indistinct & 4 & 7,8 \\
\hline Spiculated & 15 & 29,4 \\
\hline Associated Features & $n$ & $\%$ \\
\hline None & 73 & 64 \\
\hline Nipple retraction & 6 & 5,2 \\
\hline Skin retraction & 6 & 5,2 \\
\hline Skin thickening & 9 & 7,9 \\
\hline Axillary adenopathy & 9 & 7,9 \\
\hline Trabecular thickening & 4 & 3,5 \\
\hline
\end{tabular}

the most common mammographic finding, seen in 52 lesions (45.6\%). The second most common finding was masses, found in 51 cases $(44.7 \%)$. Mammography identified 3 out of 17 (17.6\%) multifocal tumors and 4 out of $15(22 \%)$ multicentric tumors.
The malignant tumor was identified in 109 among the 113 patients (96.5\%) who performed ultrasound. Ultrasound characterized bilateral tumors in only one case. The frequencies of ultrasonography findings are described on Table 2. Most of the malignant tumors presented as masses at ultrasound ( $n=109 ; 94.8 \%)$. Ultrasonography identified 9 out of 15 (60\%) multifocal tumors and 7 out of 15 (46\%) multicentric tumors.

The MRI was positive in 103 of 105 patients (98\%) who were evaluated by this method. The two cases that had a negative MRI presented grouped calcifications diagnosed only by mammography. MRI characterized the two lesions in both patients who had bilateral tumors. MRI findings are described on Table 3. Most malignant

Table 2 Description of ultrasonographic findings

\begin{tabular}{|c|c|c|}
\hline Sonographic findings $(n=115)$ & $\mathrm{n}$ & $\%$ \\
\hline Mass & 86 & 74,8 \\
\hline Mass with calcifications & 15 & 13.0 \\
\hline Mass with architectural distortion & 4 & 3,5 \\
\hline Architectural distortion & 1 & 0,9 \\
\hline Architectural distortion with calcifications & 1 & 0,9 \\
\hline Mass with architectural distortion and calcifications & 4 & 3,5 \\
\hline Negative findings & 4 & 3,5 \\
\hline Masses $(n=109)$ & $\mathrm{n}$ & $\%$ \\
\hline \multicolumn{3}{|l|}{ Shape } \\
\hline Round & 2 & 1,8 \\
\hline Oval & 36 & 32,9 \\
\hline Irregular & 59 & 54,1 \\
\hline \multicolumn{3}{|l|}{ Margin } \\
\hline Circunscribed & 28 & 25,7 \\
\hline Indistinct & 38 & 34,8 \\
\hline Angulated & 3 & 2,7 \\
\hline Microlobulated & 7 & 6,4 \\
\hline Spiculated & 11 & 10 \\
\hline \multicolumn{3}{|l|}{ Echo Pattern } \\
\hline Hypoecoic & 86 & 74,8 \\
\hline Isoecoic & 1 & 0,9 \\
\hline Hyperecoic & 1 & 0,9 \\
\hline Complex cystic and solid & 11 & 9,6 \\
\hline \multicolumn{3}{|l|}{ Associated Features $(n=115)$} \\
\hline None & 70 & 60,9 \\
\hline Edema & 1 & 0,9 \\
\hline Axillary adenopathy & 23 & 20 \\
\hline Axillary adenopathy and edema & 1 & 0,9 \\
\hline Skin thickening and retraction & 1 & 0,9 \\
\hline Skin thickening, edema and axillary adenopathy & 3 & 2,6 \\
\hline
\end{tabular}


Table 3 Description of MRI findings

\begin{tabular}{|c|c|c|}
\hline MRI findings $(n=107)$ & $n$ & $\%$ \\
\hline Mass & 67 & 62,6 \\
\hline Mass and non-mass enhancement & 21 & 19,6 \\
\hline Non-mass enhancement & 17 & 15,9 \\
\hline Negative findings & 2 & 1,8 \\
\hline Masses $(n=88)$ & $n$ & $\%$ \\
\hline \multicolumn{3}{|l|}{ Shape } \\
\hline Round & 3 & 3,4 \\
\hline Oval & 43 & 48,9 \\
\hline Irregular & 41 & 46,6 \\
\hline \multicolumn{3}{|l|}{ Margin } \\
\hline Circunscribed & 8 & 9,1 \\
\hline Irregular & 54 & 61,4 \\
\hline Spiculated & 18 & 20,4 \\
\hline \multicolumn{3}{|l|}{ Internal enhancement } \\
\hline Homogeneous & 11 & 12,5 \\
\hline Heterogeneous & 58 & 65.8 \\
\hline Rim enhancement & 14 & 15,9 \\
\hline \multicolumn{3}{|l|}{ Kinetic curve $(n=60)$} \\
\hline Persistent & 4 & 4,5 \\
\hline Plateau & 21 & 23,8 \\
\hline Washout & 35 & 39,8 \\
\hline Non-mass enhancement $(n=38)$ & $n$ & $\%$ \\
\hline \multicolumn{3}{|l|}{ Distribution } \\
\hline Focal & 3 & 7,9 \\
\hline Linear & 15 & 39,4 \\
\hline Segmental & 10 & 26,2 \\
\hline Regional & 5 & 13,1 \\
\hline Diffuse & 1 & 2,6 \\
\hline Multiple regions & 2 & 5,3 \\
\hline \multicolumn{3}{|l|}{ Internal enhancement } \\
\hline Homogeneous & 7 & 18,4 \\
\hline Heterogeneous & 20 & 52,6 \\
\hline Clumped & 3 & 7,9 \\
\hline Cluestered rings & 1 & 2,6 \\
\hline Associated Features & $n$ & $\%$ \\
\hline None & 52 & 48,6 \\
\hline Skin invasion & 16 & 14,9 \\
\hline Nipple invasion & 12 & 31,6 \\
\hline Pectoralis muscle invasion & 6 & 15,8 \\
\hline Axillary adenopathy & 37 & 34,6 \\
\hline
\end{tabular}

tumors presented as mass lesion $(n=67 ; 62.6 \%)$. MRI identified 13 out of 15 (86\%) multifocal tumors and 10 out of $16(62 \%)$ multicentric tumors.

\section{Correlation of image findings, histology and molecular subtypes}

Table 4 describes the correlation between the assessed BIRADS categories at imaging methods and the histological results. The 9 lesions that had false-negative results at mammography (categories 1 and 2) corresponded to invasive carcinomas. All DCIS cases had suspicious findings at mammography (categories 4 and 5). At ultrasound, 3 out of the 5 false-negative represented DCIS, and 13 invasive carcinomas were classified as probably benign (category 3 ). At MRI, all invasive carcinomas were characterized as suspicious at MRI (categories 4 and 5) and the two falsenegative cases corresponded to DCIS.

There was no statistically significant association between imaging findings and molecular subtypes in the present study. The correlation between the molecular subtypes and mass shape at ultrasound showed that round or oval masses were more common in triple negative subtype (Fig. 1), while irregular masses were more common in luminal B subtype, however this difference was not statistically significant (Table 5). The presence of calcifications at mammography was more common in HER2 subtype (Fig. 2), while it was less common in triple-negative subtype, however this difference was not statistically significant (Table 6).

\section{Discussion}

The diagnosis of malignant neoplasm of the breast in women aged under 40 years is sometimes more difficult

Table 4 Correlation between BIRADS categories at imaging methods (mammography, ultrasound and MRI) and tumor histologic types

\begin{tabular}{|c|c|c|c|c|}
\hline & \multicolumn{3}{|c|}{ Histologic types } & \multirow[b]{2}{*}{ Total } \\
\hline & $\begin{array}{l}\text { NST Invasive } \\
\text { carcinoma }\end{array}$ & CDIS & $\begin{array}{l}\text { Special types } \\
\text { invasive } \\
\text { carcinomas }\end{array}$ & \\
\hline \multicolumn{5}{|c|}{$\begin{array}{l}\text { BIRADS Category }{ }^{a} \\
\text { Mammography }\end{array}$} \\
\hline 1 e 2 & $8(12 \%)$ & 0 & $1(7 \%)$ & $9(9 \%)$ \\
\hline 0 e 3 & 13 (19\%) & 0 & $6(40 \%)$ & 19 (21\%) \\
\hline 4 & $26(38 \%)$ & $9(100 \%)$ & $6(40 \%)$ & $41(45 \%)$ \\
\hline 5 & $21(31 \%)$ & 0 & $2(13 \%)$ & $23(25 \%)$ \\
\hline \multicolumn{5}{|c|}{ Ultrasound } \\
\hline $1+2$ & $1(2 \%)$ & $3(60 \%)$ & $1(6 \%)$ & $5(6 \%)$ \\
\hline 3 & 10 (17\%) & 0 & $3(18 \%)$ & $13(16 \%)$ \\
\hline 4 & 48 (81\%) & $2(40 \%)$ & $13(76 \%)$ & 63 (78\%) \\
\hline \multicolumn{5}{|l|}{ MRI } \\
\hline 2 & 0 & $2(50 \%)$ & 0 & $2(5 \%)$ \\
\hline 4 & $18(56 \%)$ & $2(50 \%)$ & $2(40 \%)$ & $22(54 \%)$ \\
\hline 5 & 14 (44\%) & 0 & $3(60 \%)$ & 17 (41\%) \\
\hline
\end{tabular}

${ }^{a}$ Category 6 lesions were excluded from analysis 


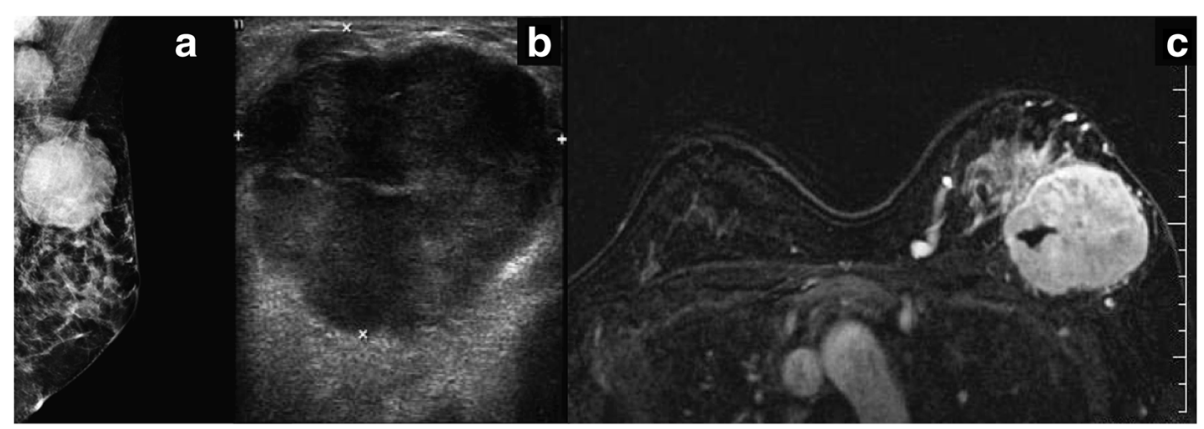

Fig. 1 35-year-old women with no special type invasive carcinoma in the left breast, triple-negative molecular subtype, presenting as a round circumscribed mass with enlarged axillary lymph nodes at mammography a hypoechoic, round circumscribed mass at ultrasound $\mathbf{b}$ and round circumscribed mass with heterogeneous enhancement at magnetic resonance imaging $\mathbf{c}$

than performed in women of older age. In this age group malignant lesions are less common, difficult to detect and can more easily be interpreted as benign lesions. In the current study, $61 \%$ of the patients had negative family history of breast or ovarian cancer and $75.6 \%$ was symptomatic at diagnosis, which is consistent with other studies $[9,10]$.

Our results showed that mammography can provide essential information on the diagnosis of breast cancer in women under 40 years. Although mammography traditionally has a lower sensitivity in young patients [11], technical advances related to the use of digital mammography enabled a considerable improvement in the mammographic analysis, especially in dense breasts. Thus, it is necessary to re-evaluate its value in the assessment of younger women, especially those with breast symptoms. In our study, $92 \%$ of the mammograms showed positive findings. These results corroborate the literature and confirm the importance of mammography in patients with symptoms or relevant sonographic findings, since this method can detect the presence of suspicious calcifications, that sometimes may be associated with probably benign findings at ultrasound, which could delay the diagnosis.

Ultrasonography represented the most common method used in the initial evaluation of breast lesions in young patients and was positive in the detection of malignant lesions in $96.5 \%$ of cases. In our study, the sensitivity of ultrasound to detect disorders in young breast was slightly higher than mammography (92.2\%). Zadelis and Houssami [12] reported $84 \%$ sensitivity in detecting lesions at

Table 5 Correlation between mass shape at ultrasound and molecular subtypes $(n=92)$

\begin{tabular}{|c|c|c|c|c|}
\hline \multirow[b]{2}{*}{$\begin{array}{l}\text { Mass shape at } \\
\text { ultrasound }\end{array}$} & \multicolumn{4}{|c|}{ Molecular subtypes } \\
\hline & $\begin{array}{l}\text { Luminal A } \\
(n=14)\end{array}$ & $\begin{array}{l}\text { Luminal B } \\
(n=48)\end{array}$ & $\begin{array}{l}\text { HER 2 } \\
(n=10)\end{array}$ & $\begin{array}{l}\text { Triple-negative } \\
(n=23)\end{array}$ \\
\hline Round or oval & $6(42.9)$ & $10(22.2)$ & $4(40.0)$ & 16(69.6) \\
\hline Irregular & $8(57.1)$ & 35(77.8) & $6(60.0)$ & $7(30,4)$ \\
\hline
\end{tabular}

$p>0.05$ ultrasound, compared to $76 \%$ at mammography. However, Di Nubila et al. [13] also found slightly higher sensitivity of ultrasound compared to mammography $(88.7 \%$ vs 84.9\%). Despite all these findings, the use of ultrasound as the initial single method in the evaluation of breasts in young patients should be made with caution, especially in those with palpable changes or other breast symptoms, in whom it should be associated with mammography.

The MRI is especially used as a complementary method for staging of malignant lesions. This method has the highest sensitivity to assess the tumor extent and the detection of multifocal and multicentric disease. MRI was also able to indicate a greater number of associated findings, playing an important role in the locoregional staging of breast cancer and its treatment planning [14-17]. Sardanelli et al. [15], showed that MRI was more sensitive $(81 \%)$ compared to mammography $(60 \%)$ in the detection of additional tumor foci in nonfatty breasts. This reinforces the importance of MRI in the study of young patients, especially those with highrisk for breast cancer. Kuhl et al. [14] showed that the sensitivity for detection of breast cancer in high-risk patients was 33\%, 37\% and 92\%, respectively, for mammography, ultrasound and MRI. In the current study, MRI showed better performance than mammography and ultrasound in suggesting histologically confirmed multifocal and multicentric tumors.

In the group of young women, although the luminal molecular type is still the most common, there is a higher prevalence of negative hormone receptor tumors, such as HER2 and triple-negative molecular subtypes. Despite there was no statistically significant difference in the imaging findings of molecular subtypes, we observed that the presence of calcifications at mammography was more common in HER2 subtype and oval/round mass at ultrasound was more common in triple-negative subtype, which was also described in previous studies $[18,19]$.

False-negative results were observed in all imaging methods. Discordance between the assessment of imaging 


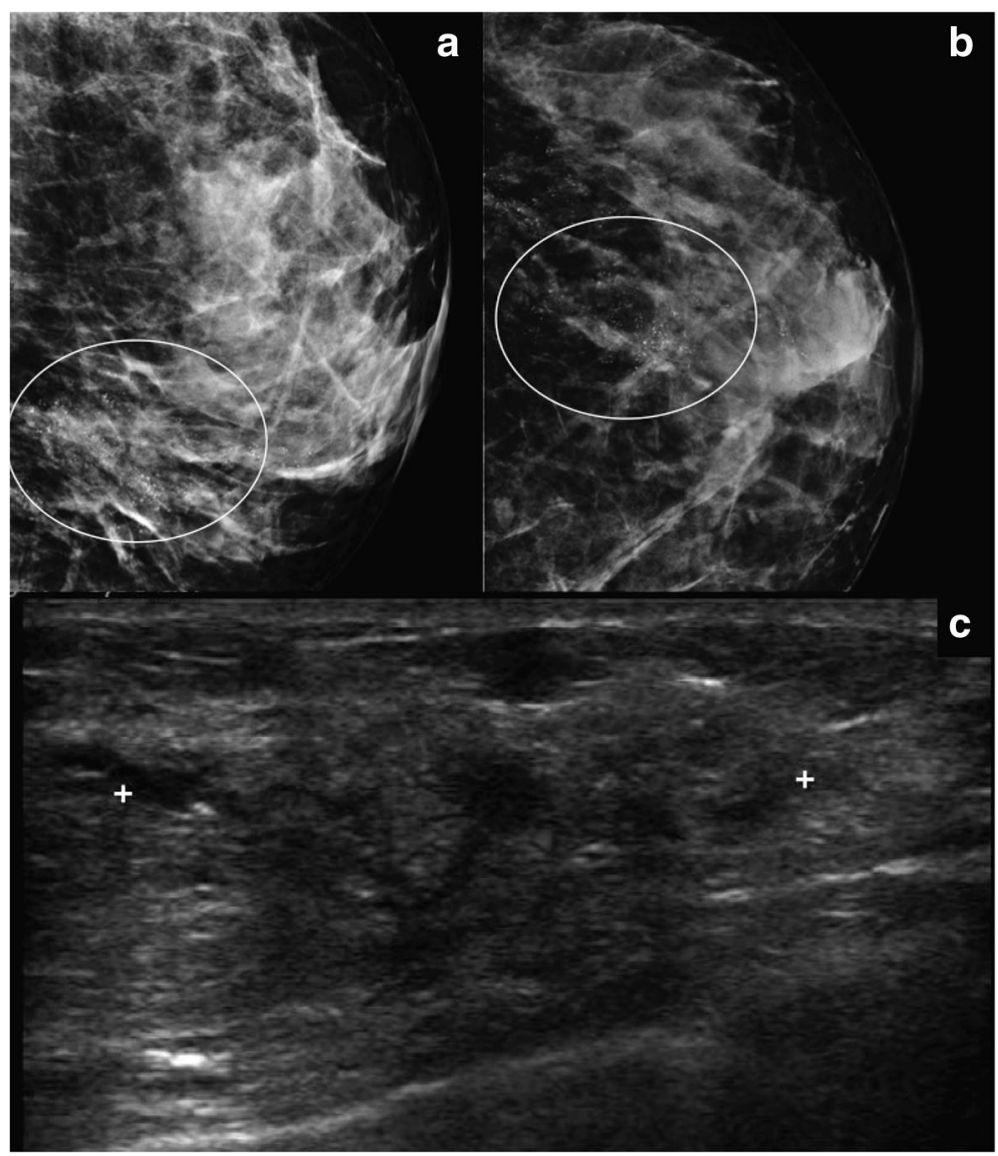

Fig. 2 32-year-old women with no special type invasive carcinoma in the left breast, Her-2 molecular subtype, associated with ductal carcinoma in situ (DCIS), presenting as pleomorphic calcifications with segmental distribution at mammography (white circles in $\mathbf{a}$ and $\mathbf{b}$ ), and as hypoechoic ill-defined area of architectural distortion at ultrasound $\mathbf{c}$

methods and pathological examination may be related to the type of tumor and breast density. Young patients with dense breast can show false-negative results because the fibroglandular breast tissue may obscure the tumor, especially for non-calcified carcinomas. At ultrasonography, false-negative results are associated with non-mass lesions, such as DCIS and lobular carcinoma, or well-circumscribed masses, such as triple-negative NST breast carcinoma, mucinous carcinoma and medullary carcinoma. At MRI, falsenegative results are usually associated with low and intermediate-grade DCIS, which can present only as suspicious calcifications at mammography.

Table 6 Correlation between presence of calcifications at mammography and molecular subtypes $(n=87)$

\begin{tabular}{lllll}
\hline $\begin{array}{l}\text { Presence of } \\
\text { calcifications at } \\
\text { mammography }\end{array}$ & \multicolumn{4}{l}{ Molecular subtypes } \\
\cline { 2 - 5 } & $\begin{array}{l}\text { Luminal A } \\
(n=13)\end{array}$ & $\begin{array}{l}\text { Luminal B } \\
(n=44)\end{array}$ & $\begin{array}{l}\text { HER 2 } \\
(n=10)\end{array}$ & $\begin{array}{l}\text { Triple-negative } \\
(n=20)\end{array}$ \\
\hline Yes & $6(46.1)$ & $21(47.7)$ & $7(70.0)$ & $6(30.0)$ \\
No & $7(53.9)$ & $23(52.3)$ & $3(30.0)$ & $14(70.0)$ \\
\hline
\end{tabular}

$p>0.05$
This study has the limitations of a retrospective study, based on information retrieved from non-standard medical records and imaging exams that were sometimes performed in other diagnostic centers.

\section{Conclusions}

This study demonstrated that imaging methods play a fundamental role in the characterization of cases of breast cancer diagnosed in patients younger than 40 years. Although ultrasound has presented a slightly superior to mammography sensitivity, the latter added important information, especially in the evaluation of DCIS. MRI was superior to other methods in the evaluation of multifocal and multicentric lesions. We did not observe statistically significant differences between the imaging findings and the molecular subtype of breast cancer in young patients. The discussion of these findings is essential to alert the younger population about the importance of the disease and to the development of effective early diagnosis in this population. 


\section{Abbreviations}

ACR-BIRADS: American college of radiology - breast imaging report and data system; DCIS: Ductal carcinoma in situ; MRI: Magnetic resonance imaging NST: No Special Type; WHO: World Health Organization

\section{Acknowledgements}

None.

\section{Funding}

No funding received.

\section{Availability of data and materials}

The datasets during and/or analysed during the current study available from the corresponding author on reasonable request

\section{Authors' contributions}

DSGE, JAS, RC and EFM designed the research; DSGE, JAS, AGVB and LG performed the research; DSGE, JAS, RC and AGVB analyzed the data; and all authors wrote/revised the paper. All authors read and approved the final manuscript.

\section{Competing interests}

The authors declared that they have no competing interests. All procedure performed in these study were in accordance with the ethical standards of the institutional research committee and with the 1964 Helsinki declaration and its later amendments.

\section{Consent for publication}

Not applicable.

\section{Ethics approval and consent to participate}

This project received approval from the institution's Research Ethics Committee (no. 1555/11).

\section{Publisher's Note}

Springer Nature remains neutral with regard to jurisdictional claims in published maps and institutional affiliations.

Received: 28 September 2016 Accepted: 5 May 2017

Published online: 12 May 2017

\section{References}

1. Agarwal G, Pradeep PV, Aggarwal V, Yip CH, Cheung PSY. Spectrum of breast cancer in Asian women. World J Surg. 2007;31(5):1031-40.

2. Villarreal-Garza C, Aguila C, Magallanes-Hoyos MC, Mohar A, Bargallo E, Meneses A, et al. Breast cancer in young women in Latin America: an unmet, growing burden. Oncologist. 2013;18(Suppl):26-34.

3. Anders CK, Hsu DS, Broadwater G, Acharya CR, Foekens JA, Zhang Y, et al. Young age at diagnosis correlates with worse prognosis and defines a subset of breast cancers with shared patterns of gene expression. J Clin Oncol. 2008;26(20):3324-30.

4. Gewefel H, Salhia B. Breast cancer in adolescent and young adult women Clin Breast Cancer. 2014;14(6):390-5.

5. Samphao S, Wheeler AJ, Rafferty E, Michaelson JS, Specht MC, Gadd MA et al. Diagnosis of breast cancer in women age 40 and younger: delays in diagnosis result from underuse of genetic testing and breast imaging. Am J Surg. 2009;198(4):538-43.

6. Lee H-B, Han W. Unique features of young age breast cancer and its management. J Breast Cancer. 2014;17(4):301.

7. D'Orsi CJ, Sickles EA, Mendelson EB, Morris EA, et al. ACR BI-RADS Atlas, Breast Imaging Reporting and Data System. Reston: American College of Radiology; 2013

8. Lakhani S, Ellis I, Schnitt S, Tan PH, Van de Vijver MJ. WHO Classification of Tumours of the Breast. 4th ed. Lyon: IARC Press; 2012.

9. Eccles BK, Copson ER, Cutress RI, Maishman T, Altman DG, Simmonds P, et al. Family history and outcome of young patients with breast cancer in the UK (POSH study). Br J Surg. 2015;102(8):924-35.

10. Ruddy KJ, Gelber S, Tamimi RM, Schapira L, Come SE, Meyer ME, et al. Breast cancer presentation and diagnostic delays in young women. Cancer. 2014 120(1):20-5
11. Foxcroft LM, Evans EB, Porter AJ. The diagnosis of breast cancer in women younger than 40. Breast. 2004;13(4):297-306.

12. Zadelis S, Houssami N. Mammographic features of breast cancer in young symptomatic women. Australas Radiol. 2003:47(4):404-8.

13. Di Nubila B, Cassano E, Urban LABD, Fedele P, Abbate F, Maisonneuve P, et al. Radiological features and pathological-biological correlations in 348 women with breast cancer under 35 years old. Breast. 2006;15(6):744-53.

14. Kuhl C, Weigel S, Schrading S, Arand B, Bieling H, König R, et al. Prospective multicenter cohort study to refine management recommendations for women at elevated familial risk of breast cancer: The EVA trial. J Clin Oncol. 2010;28(9):1450-7.

15. Sardanelli F, Giuseppetti GM, Panizza P, Bazzocchi M, Fausto A, Simonetti G, et al. Sensitivity of MRI versus mammography for detecting foci of multifocal, multicentric breast cancer in fatty and dense breasts using the whole-breast pathologic examination as a gold standard. Am J Roentgenol. 2004;183(4):1149-57.

16. Salem DS, Kamal RM, Mansour SM, Salah LA, Wessam R. Breast imaging in the young: The role of magnetic resonance imaging in breast cancer screening, diagnosis and follow-up. J Thorac Dis. 2013;5(Suppl1):S9-18.

17. An YY, Kim SH, Kang BJ. Characteristic features and usefulness of MRI in breast cancer in patients under 40 years old: correlations with conventional imaging and prognostic factors. Breast Cancer. 2014;21(3):302-15.

18. Bullier B, MacGrogan G, Bonnefoi H, Hurtevent-Labrot $G$, Lhomme E, Brouste $V$, et al. Imaging features of sporadic breast cancer in women under 40 years old: 97 cases. Eur Radiol. 2013;23(12):3237-45.

19. An YY, Kim SH, Kang BJ, Park CS, Jung NY, Kim JY. Breast cancer in very young women ( $<30$ years): correlation of imaging features with clinicopathological features and immunohistochemical subtypes. Eur J Radiol. 2015:84(10):1894-902.

\section{Submit your next manuscript to BioMed Central and we will help you at every step:}

- We accept pre-submission inquiries

- Our selector tool helps you to find the most relevant journal

- We provide round the clock customer support

- Convenient online submission

- Thorough peer review

- Inclusion in PubMed and all major indexing services

- Maximum visibility for your research

Submit your manuscript at www.biomedcentral.com/submit
Biomed Central 